Volume 1, Issue 2, October 2020, p. 33 - 38

P-ISSN 2745-6498, E-ISSN 2745-8008

\title{
Kualitas Hidup Ditinjau dari Tingkat Kecemasan Pasien Penderita Ulkus Diabetikum
}

\author{
Herno Setiawan ${ }^{1}$, Hamid Mukhlis ${ }^{2 *}$, Dian Arif Wahyudi ${ }^{3}$, Rika Damayanti ${ }^{4}$ \\ ${ }^{1,3}$ Program Studi Ilmu Keperawatan Fakultas Kesehatan Universitas Aisyah Pringsewu \\ $\left.{ }^{2}\right)$ Program Studi Sarjana Psikologi Fakultas Sosial dan Bisnis Universitas Aisyah Pringsewu \\ ${ }^{4}$ Universitas Islam Negeri Radin Intan Bandarlampung
}

\section{ARTICLE INFO}

\section{Keyword:}

Anxiety Level

Quality Of Life

Diabetic Ulcer

\section{*) corresponding author}

Program Studi Sarjana Psikologi Fakultas Sosial dan Bisnis Universitas Aisyah Pringsewu

Jl. A. Yani No. 1A Tambahrejo Kecamatan Gadingrejo Kabupaten Pringsewu Lampung 35372

Email:

me@hamidmukhlis.id

\section{A B S T R A C T}

Diabetic foot ulcer is a chronic wound in the lower area of the ankle, which causes anxiety, increases morbidity, mortality, and reduces the quality of life. This research aims to know correlation between levels of anxiety with the quality of life of diabetic ulcer sufferers in dr. A. Dadi Tjokrodipo Hospital Bandar Lampung City in 2020. This research uses quantitative research method with a cross-sectional approach. The population in this study was the sufferer of the diabetic ulcer by 31 sufferers, with a sample number are 31 respondents. Bivariate analysis using Chi Square test analysis with a limit of 95 percent of P-value obtained 0.028 less than 0.05 (P-value less than 0.05), so that Ho rejected this indicates that there is a relationship between levels of anxiety with the quality of life of diabetic ulcer sufferers in dr. A. Dadi Tjokrodipo Hospital Bandar Lampung City in 2020. The results of this research are expected to be recomendation for the community, especially diabetic ulcer sufferers to be able to think positively in dealing with problems such as anxiety. Therefore, health workers can provide the treatment of patient anxiety problems by providing counseling, support and motivating sufferers to avoid affecting the quality of life of sufferers with the psychological problems.

This open access article is under the CC-BY-SA license.

\section{A B S T R A K}

Ulkus kaki diabetik adalah luka kronik pada daerah bawah pergelangan kaki, yang menyebabkan kecemasan, meningkatkan morbiditas, mortalitas, dan mengurangi kualitas hidup. Penelitian ini bertujuan untuk mengetahui hubungan antara tingkat kecemasan dengan kualitas hidup penderita ulkus diabetikum di Rumah Sakit Daerah dr. A. Dadi Tjokrodipo Kota Bandar Lampung tahun 2020. Metodologi penelitian ini menggunakan jenis penelitian kuantitatif dengan pendekatan cross-sectional. Populasi dalam penelitian ini adalah seluruh penderita ulkus diabetikum yang dirawat sebanyak 31 penderita, dengan jumlah sampel 31 responden. Analisis bivariat menggunakan analisis uji Chi Square dengan batas kemaknaan 95 persen didapatkan p-value 0,028 (p-value kurang dari 0,05), sehingga Ho ditolak hal ini menunjukkan bahwa terdapat hubungan tingkat kecemasan dengan kualitas hidup penderita ulkus diabetikum di Rumah Sakit dr. A. Dadi Tjokrodipo Kota Bandar Lampung tahun 2020. Hasil penelitian ini diharapkan menjadi masukan bagi masyarakat khususnya penderita ulkus diabetikum untuk dapat berfikir positif dalam menangani permasalah seperti kecemasan. Oleh karena itu petugas kesehatan dapat memberikan penanganan terhadap masalah kecemasan pasien dengan memberikan konseling, support dan memotivasi penderita agar tidak mempengaruhi kualitas hidup penderita dengan permasalahan psikologi tersebut. 


\section{PENDAHULUAN}

Diabetes Melitus (DM) merupakan kelompok penyakit metabolik dengan karakteristik meningkatnya kadar gula dalam darah (hiperglikemia) yang terjadi karena kelainan sekresi insulin, kerja insulin atau kedua-duanya (Farrell, 2017). Kejadian diabetes terjadi pada usia diatas 18 tahun meningkat dari 4,7\% pad tahun 1980 menjadi 8,5\% pada tahun 2014 dan tahun 2016 diperkirakan 1,6 juta kematian akibat (utama) diabetes dan pada 2012 2,2 juta kematian disumbang oleh gula darah tingi (WHO, 2018).

International Diabetes Federation (IDF) Atlas 2017 melaporkan bahwa epidemik diabetes di Indonesia masih menunjukkan kecenderungan meningkat. Indonesia adalah negara peringkat keenam di dunia dengan jumlah penyandang diabetes usia 20-79 tahun sekitar 10,3 juta orang. Sehingga diperkirakan jumlah penderita ulkus diabetikum sebesar 2,6 juta orang. Riset Kesehatan Dasar (Riskesdas) memperlihatkan angka prevalensi diabetes yang cukup signifikan, yaitu dari 6,9\% di tahun 2013 menjadi 8,5\% di tahun 2018; sehingga estimasi jumlah penderita di Indonesia mencapai 16 juta orang, dan 4 juta orang diperkirakan menderita ulkus diabetikum (Depkes, 2018).

Ulkus diabetikum, infeksi, amputasi, dan kematian merupakan komplikasi DM yang serius dan memerlukan biaya yang tidak sedikit dan perawatan yang lama (Decroli, 2019). Tingkat kejadian ulkus diabetikum adalah sekitar $25 \%$ dari populasi penderita DM yang ada. Ulkus kaki pada penderita diabetes disebabkan terutama oleh neuropati (motorik, sensorik, dan otonom) dan/atau iskemia, serta penyulit infeksi. Hilangnya sensasi nyeri ini dapat menyebabkan luka tanpa disadari, kemudian luka berkembang menjadi ulkus. Kaki yang mengalami ulkus sebagian besar dilakukan amputasi ekstremitas (85\% dari amputasi ekstremitas). Risiko amputasi sebesar $10-30 \mathrm{kali}$ lebih tinggi pada pasien diabetes dibandingkan dengan populasi umum, dan secara global diperkirakan satu juta pasien mengalami beberapa amputasi ekstremitas bawah setiap tahunnya (Bilous dan Donelly, 2014).

Ulkus diabetikum merupakan komplikasi dari penyakit diabetes mellitus (DM) yang berdampak pada keadaan fisik, psikologi, sosial dan ekonomi. Dampak terjadi pada fisik yang timbul berupa kelainan bentuk kaki, nyeri, dan infeksi kaki, bahkan dapat berpotensi amputasi, sedangkan permasalahan psikologis yang muncul dapat berupa gangguan kecemasan, ini dapat muncul disebabkan oleh penyembuhan ulkus yang dialami oleh penderita selama bertahun-tahun (Lemone et al, 2017).

Beberapa penelitian menunjukkan pasien DM dengan ulkus kaki lebih banyak yang mengalami depresi dan memiliki kualitas hidup yang buruk dibandingkan pasien DM tanpa komplikasi tersebut. Depresi pada pasien DM dijumpai lebih tinggi bila ada komorbiditas atau komplikasi. Pasien dengan ulkus kaki diabetik mempunyai berbagai derajat depresi. Menurut Salome et al (2011), sebanyak 64\% pasien mengalami depresi sedang dan 10\% mengalami depresi berat dengan gejala yang terbanyak adalah membenci diri sendiri, merasa gagal, distorsi kesan mengenai tubuhnya (body image), dan penurunan libido.

Pasien Ulkus diabetikum secara psikologis biasanya akan mengalami stres akibat dari infeksi pada ulkus maupun prosedur pembedahan. Hal itu akan meningkatkan kadar gula darah dan mungkin menjadi pencetus ketoasidosis diabetikum dan hiperglikemi hiperosmolar nonketonik. Emosional stress mempunyai pengaruh negatif terhadap kontrol gula darah yang baik. Peningkatan hormon stres juga dapat berdampak pada peningkatan gula darah (Honan, 2019). Proses penyembuhan ulkus yang membutuhkan waktu yang lama dan biaya perawatan yang meningkat akan menyebabkan stres emosional, psikologis dan finansial (Lemone et al, 2017).

Penelitian di Indonesia melaporkan bahwa angka kematian ulkus ganggren pada penyandang DM berkisar antara $17-32 \%$, sedangkan angka yang diamputasi berkisar antara $15-30 \%$. Para ahli diabetes memperkirakan 50\% sampai $75 \%$ kejadian amputasi dapat dihindarkan dengan perawatan kaki yang baik (Situmorang, 2009). Jika amputasi merupakan pilihan tatalaksana untuk kaki diabetik, bukan hanya estetika yang hilang, melainkan rasa percaya diri juga bisa hilang sebagai konsekuensi amputasi tersebut (Lemone et al, 2017). Menurut penelitian yang dilakukan oleh Utami dkk (2014), pasien dengan ulkus diabetikum yang memiliki tingkat kecemasan sedang mempunyai kualitas hidup yang rendah.

Dari hasil penelitian yang dilakukan oleh Suryani (2016), bahwa hubungan antara tingkat kecemasan dengan kualitas hidup adalah berlawanan, artinya semakin tinggi tingkat kecemasan maka semakin rendah kualitas hidup manusia. Seseorang dengan gangguan kecemasan mengalami kerusakan pada kualitas dan fungsi hidup (Keliat dan Pasaribu, 2016).

Menurut Townsend dan Morgan (2018), kecemasan muncul dari kekacauan dan kebingungan yang ada di dunia. Ketakutan akan sesuatu yang tidak diketahui dan kondisi yang membingungkan merupakan tempat yang sempurna untuk kecamasan mengakar dan berkembang. Kecemasan dan kesedihan merupakan dua respon psikologi utama dari stress. Konsep adaptasi stres merupakan respon individu untuk menghadapi situasi stres yang dipengaruhi oleh faktor psikologi, persepsi seseorang terhadap stres, dan berbagai faktor predisposisi seperti keturunan, tempramen, pola asuh, kematangan perkembangan, koping strategi yang digunakan, serta sistem dukungan dan kepedulian antar sesama. Seseorang dengan ulkus diabetikum akan mengalami kondisi stres yang digambarkan dengan kecemasan maupun kesedihan (Mukhlis, H., dkk, 2020).

Ulkus kaki diabetik merupakan luka kronik pada daerah bawah pergelangan kaki, yang meningkatkan morbiditas, mortalitas, dan mengurangi kualitas hidup (Soelistijo dkk, 2015). Menurut Polonsky (2000, dalam Yusra, 2011), kualitas hidup didefinisikan sebagai perasaan individu tentang kesehatan dan kesejahteraannya dalam area yang luas meliputi fungsi fisik, fungsi psikologis dan fungsi sosial.

Berdasarkan hasil prasurvey yang dilakukan di Rumah Sakit Daerah A. Dadi Tjokrodipo pada tanggal 12 November 2019, pada saat prasurvey ada 2 pasien ulkus diabetikum yang dirawat di Rumah Sakit Daerah A. Dadi Tjokrodipo. Peneliti melakukan wawancara terhadap 2 responden penderita ulkus diabetikum yang sedang dirawat, didapatkan bahwa penderita mengalami masalah psikologis seperti pasien berfikir mengenai lukanya yang sudah lama tidak sembuh, biaya yang tidak sedikit dan tempat berobat yang tepat, serta khawatir terhadap tata laksana pengobatan yang mungkin ketahap amputasi karena kondisi lukanya. Pasien juga mengalami masalah fisik seperti nyeri saat berjalan, sehingga menggangu aktivitasnya, serta merasa malu kepada orang lain karena kondisi luka ulkus diabetikum (Nur, M., \& Mukhlis, H. 2020).

Berdasarkan wawancara pada 2 penderita ulkus diabetikum yang mengalami permasalahan berat, dimaksudkan bahwa penderita tersebut mengalami permasalahan fisik, psikologi, ekonomi dan sosial yang dapat dikatakan kualitas hidup yang buruk. Permasalahan yang dialami penderita terjadi secara kronik selama berbulanbulan, merasakan khawatir, cemas terhadap penyakit yang dideritanya dan merasa minder, kurang percaya diri di 
lingkungan rumah, perubahan peran dirumah karena sakit yang dideritanya, Penderita juga terbebani dengan permasalahan ekonomi akibat sakit yang diderita, sehingga menimbulkan kualitas hidup yang buruk bagi penderita ulkus diabetikum.

Berdasarkan fenomena yang terjadi di lapangan tersebut, peneliti ingin mengetahui lebih lanjut tentang permasalahan yang terjadi, dan tertarik untuk mengkaitkan permasalahan tersebut dengan penelitian yang berjudul, "Hubungan Tingkat Kecemasan Dengan Kualitas Hidup penderita Ulkus Diabetikum di Rumah Sakit Daerah dr. A. Dadi Tjokrodipo Kota Bandar Lampung".

\section{METODE}

Penelitian ini merupakan jenis penelitian kuantitatif yang menggunakan desain penelitian korelasi yang pada hakikatnya digunakan untuk mengetahui hubungan antar variabel. Dengan menggunakan pendekatan cross-sectional maka penelitian membutuhkan waktu yang relatif singkat, dilakukan dalam satu waktu, sekali main. Penelitian ini digunakan untuk mencari hubungan antara variabel independen dengan variabel dependen (Donsu, 2016).

Variabel dalam penelitian ini terdiri dari variabel dependen dan independen, variabel independen yaitu tingkat kecemasan penderita ulkus diabetikum sedangkan variabel dependen adalah kualitas hidup penderita ulkus diabetikum.

Populasi adalah wilayah generalisasi yang terdiri dari objek/subjek yang mempunyai kuantitas dan karakteristik tertentu yang ditetapkan oleh peneliti untuk dipelajari dan ditarik kesimpulannya (Sugiyono, 2014). Menurut Donsu (2017), populasi adalah seluruh objek atau subjek yang memiliki kualitas dan karakteristik tertentu yang sudah ditentukan oleh peneliti.

Berdasarkan hal tersebut, populasi dalam penelitian ini adalah seluruh penderita yang mengalami ulkus diabetikum di Rumah Sakit dr. A. Dadi Tjokrodipo Kota Bandar Lampung 2020 yang berjumlah 31 orang.

Sampel adalah bagian dari jumlah dan karakteristik yang dimiliki oleh populasi yang diteliti. Untuk itu sampel yang diambil dari populasi harus benar-benar mewakili (Sugiyono, 2014). Apabila subjeknya lebih dari 100 maka sampel dapat diambil antara 10-15\%, 20-25\% atau lebih, jika subjeknya kurang dari 100 maka sampel diambil semua (Arikunto, 2010).

Dalam penelitian ini tehnik pengambilan sampel yang digunakan adalah total sampling dengan jumlah sampel 31 responden.
Kriteria sampel yang digunakan dalam pengambilan sampel adalah sebagai berikut:

1. Pasien yang menderita ulkus diabetikum.

2. Menyetujui lembar persetujuan responden.

Penelitian ini dilakukan di Rumah Sakit dr. A. Dadi Tjokrodipo Kota Bandar Lampung dan di rumah penderita ulkus yang pernah dirawat di Rumah Sakit dr. A. Dadi Tjokrodipo Kota Bandar Lampung.

Penelitian dan pengambilan data dilakukan pada tanggal 10 sampai dengan 21 Februari tahun 2020.

Analisa univariat bertujuan untuk menjelaskan atau mendeskripsikan karakteristik setiap variabel penelitian. Bentuk analisis univariat tergantung jenis datanya. Pada umumnya dalam analisis ini hanya menghasilkan distribusi frekuensi dan presentase dari tiap variabel.

Penelitian ini menggunakan uji Chi Square, karena melihat dari skala ukur dalam Definisi Operasional yang kedua variabel menggunakan skala ordinal dan nominal. Untuk melihat hasil kemaknaaan perhitungan statistik digunakan batas kemaknaan 95\% dengan nilai p value $<0,05$ maka Ho ditolak, dan p value $>0,05$ maka Ho gagal ditolak.

\section{HASIL DAN PEMBAHASAN}

Tabel 1.

Distribusi Frekuensi Tingkat Kecemasan dam kualitas Hidup ( $\mathrm{N}=31)$

\begin{tabular}{c|ll}
\hline Tingkat Kecemasan & \multicolumn{1}{l}{ Jumlah } & Persentase (\%) \\
\hline Tidak Cemas & 9 & 29,0 \\
\hline Cemas & 22 & 71,0 \\
\hline Kualitas Hidup & & \\
\hline Baik & 10 & 32,3 \\
\hline Buruk & 21 & 67,7 \\
\hline
\end{tabular}

Berdasarkan tabel 1 terlihat bahwa tingkat kecemasan 31 responden yang ada di RSD. dr. A. Dadi Tjokrodipo Kota Bandar Lampung yang mengalami tidak cemas sebanyak 9 responden $(29,0 \%)$, dan yang mengalami cemas sebanyak 22 responden $(71,0 \%)$

Kualitas hidup pada 31 responden yang ada di RSD. dr. A. Dadi Tjokrodipo Kota Bandar Lampung yang mengalami kualitas hidup baik sebanyak 10 responden (32,3\%), dan yang mengalami kualitas hidup buruk sebanyak 21 responden $(67,7 \%)$.

\section{Tabel 2}

Hubungan Antara Tingkat Kecemasan Dengan Kualitas Hidup Penderita Ulkus Diabetikum (N=31)

\begin{tabular}{|c|c|c|c|c|c|c|c|c|c|}
\hline \multirow{3}{*}{ Tingkat Kecemasan } & \multicolumn{4}{|c|}{ Kualitas Hidup } & & & \multirow{3}{*}{$\mathrm{p}$ value } & \multirow{3}{*}{ OR } & \multirow{3}{*}{$95 \% \mathrm{CI}$ OR } \\
\hline & \multicolumn{2}{|c|}{ Tinggi } & \multicolumn{2}{|c|}{ Rendah } & \multicolumn{2}{|c|}{ Jumlah } & & & \\
\hline & $\mathrm{F}$ & $\%$ & $\mathrm{~F}$ & $\%$ & $\mathrm{~N}$ & $\%$ & & & \\
\hline Tidak Cemas & 6 & 66,7 & 3 & 33,3 & 9 & 100 & 0,028 & 9,00 & $1,55-52,266$ \\
\hline Cemas & 4 & 18,2 & 18 & 81,8 & 22 & 100 & & & \\
\hline
\end{tabular}

Berdasarkan tabel 2, dapat disimpulkan bahwa dari 9 responden yang tidak cemas terdapat $6(66,7 \%)$ responden yang mengalami kualitas hidup baik dan $3(33,3 \%)$ responden mengalami kualitas hidup buruk. Sedangkan dari 22 responden yang cemas terdapat $4(18,2 \%)$ responden mengalami kualitas hidup baik dan $18(81,8 \%)$ responden mengalami kualitas hidup buruk. Hasil analisis bivariat dengan menggunakan Uji Chi-square dimana P.Value sebesar 0,028 (OR 9,00) dapat disimpulkan bahwa ada hubungan yang bermakana antara tingkat kecemasan dengan kualitas hidup, atau responden yang mengalami cemas 9 kali berisiko 
untuk mengalami kualitas hidup buruk dibandingkan dengan responden yang tidak cemas.

\section{PEMBAHASAN}

\section{Tingkat Kecemasan}

Berdasarkan penelitian yang dilakukan, tingkat kecemasan 31 penderita ulkus diabetikum yang ada di RSD. dr. A. Dadi Tjokrodipo Kota Bandar Lampung yang mengalami tidak cemas sebanyak 9 responden atau sekitar $29 \%$, dan yang mengalami cemas sebanyak 22 responden atau sekitar $71 \%$.

Sesuai dengan teori yang disampaikan Honan (2019), pasien ulkus diabetikum secara psikologis biasanya akan mengalami kecemasan akibat dari infeksi maupun prosedur pembedahan pada ulkus yang diderita. Sedangkan menurut Lemone et al (2017), proses penyembuhan ulkus yang membutuhkan waktu yang lama dan biaya perawatan yang meningkat akan menyebabkan stres emosional, psikologis (kecemasan) dan finansial bagi penderita.

Penelitian ini sejalan dengan penelitian Suciati (2014), pada penelitiannya menunjukkan gambaran tingkat kecemasan penderita diabetes melitus dengan luka gangren sebagian kecil tidak mengalami kecemas dengan persentase $25 \%$, sebagian besar mengalami kecemasan dengan presentase $75 \%$. Hal ini sejalan dengan penelitian Darmawati dan Darlina (2017), bahwa dari 64 penderita ulkus diabetikum, terdapat 7 responden (10,9\%) mengalami tidak cemas dan 57 responden (89,1\%) responden mengalami kecemasan (Mukhlis, H. 2015).

Menurut peneliti, penderita ulkus diabetikum mempunyai masalah fisik berupa luka di kaki yang lama sembuh bahkan sampai berbau tak sedap, kelainan bentuk kaki, keterbatasan mobilitas fisik dan ketidakmampuan untuk melaksanakan fungsi baik dalam keluarga maupun masyarakat. Bila luka semakin parah, maka dapat juga dilakukan prosedur pembedahan sampai dengan amputasi kaki. Hal tersebut akan mengganggu citra tubuh penderita serta akan menyebabkan dampak psikologis berupa gangguan kecemasan yang mengakibatkan gangguan berkemih, kesemutan dan mati rasa, badan lemah dan mudah lelah, serta mengalami kesulitan tidur malam (Maesaroh, S., Mukhlis, H., \& Widyastuti, F. 2019).

\section{Kualitas Hidup}

Berdasarkan penelitian yang dilakukan, kualitas hidup 31 penderita ulkus diabetikum yang ada di RSD. dr. A. Dadi Tjokrodipo Kota Bandar Lampung yang mengalami kualitas hidup baik sebanyak 10 responden atau 32,3\%, dan yang mengalami kualitas hidup buruk sebanyak 21 responden atau sekitar $67,7 \%$.

Hal ini sejalan dengan Soelistijo dkk (2015), bahwa ulkus kaki diabetik merupakan luka kronik pada daerah bawah pergelangan kaki, yang meningkatkan morbiditas, mortalitas, dan mengurangi kualitas hidup. Menurut Aprilia (2014), ada empat aspek yang mempengaruhi kualitas hidup yaitu kesehatan fisik, psikologis, hubungan sosial dan hubungan dengan lingkungan.

Penelitian ini sejalan dengan Syarif (2012), bahwa Pasien dengan ulkus diabetikum yang memiliki kualitas hidup kurang sebanyak 19 orang atau 57,6\%, dan yang memiliki kualitas hidup baik sebanyak 14 orang atau $42,4 \%$. Sesuai dengan penelitian yang dilakukan Mairiyani, Linda. dkk (2015), bahwa pasien ulkus diabetikum yang mengalami kualitas hidup baik sebanyak 2 orang atau sekitar 6,7\%, sedangkan yang mengalami kualitas hidup kurang sebanyak 28 responden atau sekitar (93,3\%) penderita. Hal ini juga sejalan dengan penelitian Darmawati dan Darlina (2017), bahwa dari 64 penderita ulkus diabetikum, terdapat 25 responden $(39,1 \%)$ mengalami kualitas hidup baik dan 39 responden $(60,9 \%)$ responden mengalami kualitas hidup buruk.

Menurut hasil penelitian ini, kualitas hidup penderita ulkus diabetikum mengalami masalah diakarenakan adanya keterbatasan fisik penderita sehingga menurunkan kemampuan penderita untuk bekerja dan bergaul dengan orang lain. Selain itu secara psikologis penderita ulkus diabetikum mengalami masalah penampilan tubuhnya.

Hasil uji chi square didapatkan nilai $p$ value $=0,028<$ dari $\alpha(0,05)$ sehingga dapat ditarik kesimpulan bahwa ada hubungan antara tingkat kecemasan dengan kualitas hidup penderita ulkus diabetikum di Rumah Sakit Daerah dr. A. Dadi Tjokrodipo Kota Bandar Lampung tahun 2020. Hasil pengolahan data juga didapat nilai OR sebesar 9,00 yang berarti responden yang mengalami cemas beresiko mengalami kualitas hidup buruk sebesar 9 kali lebih besar dibandingkan dengan responden yang mengalami tidak cemas.

Hasil penelitian ini sesuai dengan pendapat ahli bahwa seseorang dengan gangguan kecemasan mengalami kerusakan pada kualitas dan fungsi hidup (Keliat dan Pasaribu, 2016). Orang yang mengalami kecemasan akan mengalami masalah: 1) Kesehatan fisik berupa gangguan tidur dan istirahat, kelelahan, dan bahkan dapat terjadi ketergantungan obat; 2) Kesehatan psikologis berupa perasaan negatif dan gangguan konsentrasi; 3) Sosial seperti masalah hubungan sosial; dan 4) Hubungan lingkungan berupa keamanan fisik dan partisipasi di lingkungan.

Penelitian ini sejalan dengan yang yang dilakukan oleh Utami dkk (2014), pasien dengan ulkus diabetikum yang mengalami kecemasan mempunyai kualitas hidup yang rendah. Sejalan juga dengan hasil penelitian yang dilakukan oleh Suryani (2016), bahwa hubungan antara tingkat kecemasan dengan kualitas hidup adalah berlawanan, artinya semakin tinggi tingkat kecemasan maka semakin rendah kualitas hidup manusia.

Menurut peneliti, penderita ulkus diabetikum mempunyai masalah fisik berupa luka di kaki yang lama sembuh bahkan sampai berbau tak sedap, kelainan bentuk kaki, keterbatasan mobilitas fisik dan ketidakmampuan untuk melaksanakan fungsi baik dalam keluarga maupun masyarakat. Bila luka semakin parah, maka dapat juga dilakukan prosedur pembedahan sampai dengan amputasi kaki. Hal tersebut akan mengganggu citra tubuh serta akan menyebabkan dampak psikologis berupa gangguan kecemasan yang dapat menurunkan kualitas hidup penderita, ditandai dengan keterbatasan fisik penderita sehingga menurunkan kemampuan penderita untuk bekerja dan bergaul dengan orang lain.

\section{KESIMPULAN DAN SARAN}

Berdasarkan hasil penelitian dan pembahasan terhadap 31 orang yang menjadi responden penelitian di RSUD. Dr. A. Dadi Tjokrodipo Kota Bandar Lampung dapat ditarik kesimpulan bahwa distribusi frekuensi tingkat kecemasan penderita ulkus diabetikum yang mengalami tidak cemas sebanyak 9 responden (29,0\%), yang mengalami cemas sebanyak 22 responden (71,0\%), dan distribusi frekuensi kualitas hidup penderita ulkus diabetikum yang mengalami kualitas hidup baik 10 responden (32,3\%), yang mengalami kualitas hidup buruk 21 responden (67,7\%). Hasil uji chi square didapatkan nilai $p$ value $=0,028<\alpha(0,05)$ sehingga dapat ditarik kesimpulan bahwa ada hubungan antara tingkat kecemasan dengan kualitas hidup penderita ulkus 
diabetikum di Rumah Sakit Daerah dr. A. Dadi Tjokrodipo Kota Bandar Lampung tahun 2020.

Penelitian ini sebagai bahan ajaran untuk mengembangkan infomasi dan ilmu pengetahuan, sebagai bahan acuan pembelajaran dalam merawat klien dengan masalah ulkus. Peserta didik diharapkan mengembangkan studi mengenai kemungkinan terjadinya masalah psikologis bagi klien untuk mencegah terjadinya kecemasan dan penurunan kualitas hidup penderita ulkus diabetikum.

Institusi pelayanan khususnya Rumah Sakit Daerah dr. A. Dadi Tjokrodipo Kota Bandar Lampung dan Institusi pelayanan pada umumnya diharapkan lebih memperhatikan dampak psikologis dari klien khususnya dengan masalah ulkus diabetikum. Hasil penelitian menunjukkan ada hubungan antara tingkat kecemasan dengan kualitas hidup penderita ulkus diabetikum di Rumah Sakit Daerah dr. A. Dadi Tjokrodipo Kota Bandar Lampung tahun 2020.

Bagi petugas kesehatan harus mengkaji lebih dalam mengenai aspek bio, psiko, sosial dan spiritual penderita ukus diabetikum sebagai acuan untuk memberi pelayanan kesehatan yang berkualitas. Dengarkan keluhan serta beri arahan dan motivasi kepada penderita agar semangat dalam menjalani kehidupan dengan penyakit ulkus diabetikum yang merupakan komplikasi dari diabetes mellitus (DM) agar penderita tidak mengalami gangguan mental dan psikologis.

\section{DAFTAR PUSTAKA}

Aprilia, WR. (2014). Hubungan Aktivitas Fisik Waktu Luang dengan Kualitas Hidup Pada Dewasa Madya. (Skripsi dipublikasikan). Fakultas Psikologi Universitas Islam Negeri Sultan Sarif Kasim, Riau.

Arifah, Tifani Nur. (2015). Gambaran Kualitas Hidup pada Pasien Tuberkulosis Paru di Puskesmas Padasuka Kecamatan Cibeunying Kidul Kota Bandung. Program Studi DIII Keperawatan Fakultas Pendidikan Olahraga dan Kesehatan Universitas Pendidikan Indonesia, Bandung

Arikunto, Suharsimi. (2010). Prosedur Penelitian Suatu Pendekatan Praktik. Jakarta: Rineka Cipta.

Asegab, Iqbal. (2019). Hubungan Tingkat Kecemasan Dengan Kualitas Hidup Penderita Diabetes Melitus Type II di Wilayah Kerja Puskesmas Pringsewu Kecamatan Pringsewu Tahun 2019. (Skripsi dipublikasikan). Program Studi S1 Ilmu Keperawatan Sekolah Tinggi Ilmu Kesehatan Muhammadiyah Pringsewu, Lampung.

Bilous, Rudy \& Donelly, Richard. (2014). Handbook of Diabetes 4th edition. Jakarta: Bumi Medika.

Cherney, Kristeen. (2018). Efek Kecemasan pada Tubuh. Healthline. Diunduh dari: http://www.healthline.com/health/anxiety/effects-onbody\#1.

Darmawati dan Darliana, Devi. (2017). Hubungan Kecemasan dan Depresi Dengan Kualitas Hidup Pada Pasien Ulkus Diabetik. Skripsi, Universitas Syiah Kuala, Banda Aceh.

Decroli, Eva. (2019). Diabetes Melitus Tipe 2. Pusat Penerbitan Bagian Ilmu Penyakit Dalam Fakultas Kedokteran Universitas Andalas, Padang.

Depkes. (2018).
http://www.depkes.go.ig/article/view/18121200001 Prevent_Prevent_and_Prevent_the_Voice_of_The_World_F ight_Diabetes.hmtl.

Donsu, Jenita D. T. (2017). Metodologi Penelitian Keperawatan. Yogyakarta: Pustaka Baru Press.
Selalu memberi dukungan kepada penderita ulkus diabetikum untuk mencegah pemikiran negatif yang akan berdampak pada masalah psikologi penderita ulkus. Sehingga penderita ulkus diabetikum mampu mempertahankan atau bahkan mampu meningkatkan kualitas hidup.

Agar penderita ulkus diabetikum tahu dampak psikologis yang timbul dari luka ulkus serta pengaruhnya terhadap kualitas hidup penderita. Sehingga penderita lebih rajin merawat dan rutin periksa kaki ulkus, agar tidak mengalami infeksi yang berat sampai dengan amputasi. Berperasaan positif dan mengingat Allah SWT, bahwa yang memberi sakit dan yang menyembuhkan hanyalah Allah SWT.

Agar penelitian ini dapat dilanjutkan oleh peneliti lain dengan desain yang berbeda, dan diharapkan dapat menjadi acuan dan data awal untuk memulai penelitian selanjutnya sebagai bahan referensi, peneliti selanjutnya dapat melakukan penelitian mengenai faktor-faktor yang berkaitan dengan kualitas hidup penderita ulkus diabetikum, selain itu agar peneliti selanjutnya lebih mendalami permasalahan yang terjadi pada kualitas hidup penderita ulkus diabetikum seperti masalah penampilan maupun kemampuan bekerja untuk memenuhi kebutuhan.

Farrell, Maureen. (2017). Smeltzer \& Bare's Textbook Of MedicalSurgical Nursing. Australia: Wolters Kluwer.

Honan, Linda. (2019). Focus On Adult Health Medical-Surgical Nursing Second Edition. Philadelphia: Wolters Kluwer.

Ignatavicius, Donna D. (2018). Medical-Surgical Nursing: Concepts for Interprofessional Collaborative Care, Ninth Edition. Canada: Elsevier.

Kambuaya, Noy Norman. (2012). Gambaran Penderita Ulkus Kaki Diabetik.

http://www.academia.edu/5252394/Gambaran_Penderita_ Ulkus_Kaki_Diabetik.

Keliat, Budi Ana dan Pasaribu, Jesika. (2016). Prinsip dan Praktik Keperawatan Kesehatan Jiwa Stuart. Singapura: Elsevier.

Koesmanto, S. Dalam Novandhori, D.R. (2013). Hubungan Peran Keluarga Dengan Kualitas Hidup Lansia Yang Mengalami Gangguan Fungsi Kognitif Di Desa Windunegara Kecamatan Wangon Kabupaten Banyumas. Skripsi, Universitas Jenderal Soedirman, Semarang.

Kusumadewi, Melina Dian. (2011). Peran Stresor Harian, Optimisme dan Regulasi Diri Terhadap Kualitas Hidup Individu dengan Diabetes Melitus Tipe 2. PSIKOISLAMIKA: Jurnal Psikologi Islam, 8 (1), 45. doi: http://doi.org/10.18860/psi.v0i1.1545.

Lemone, Priscilla, et al. (2017). Medical-Surgical Nursing. Volume 1-3: Critical Thinking For Person_Centered Care. Australia: Pearson Australia Yusra, Aini. (2011). Hubungan Antara Dukungan Keluarga Dengan Kualitas Hidup Pasien Diabetes Melitus Tipe 2 di Poliklinik Penyakit Dalam Rumah Sakit Umum Pusat Fatwawati Jakarta. (tesis dipublikasikan). lib.ui.ac.id, Depok.

Maesaroh, S., Mukhlis, H., \& Widyastuti, F. (2019). Efektifitas Terapi Hand Tappyng Terhadap Kecemasan pada Perempuan yang Sedang Menjalani Persalinan. Wellness And Healthy Magazine, 1(1), 7-14. 
Mairiyani, Linda dkk. (2015). Hubungan Stadium Ulkus Dengan Kualitas Hidup Pada Pasien DM Tipe II. dari: http://media.neliti.com.

Mukhlis, H. (2015). Pelatihan kebersyukuran untuk menurunkan kecemasan menghadapi ujian nasional pada siswa SMA. Gadjah Mada Journal of Professional Psychology (GamaJPP), 1(3).

Mukhlis, H., Kristianingsih, A., Fitrianti, F., Pribadi, T., Kumalasari, D., Febriyanti, H., \& Maseleno, A. (2020). The effect of expressive writing technique to stress level decrease of new student at Al-Falah Putri Islamic Boarding School, Margodadi, Tanggamus. Annals of Tropical Medicine and Health, 23, 192-200.

Notoatmodjo, S. (2012). Metodologi Penelitian Kesehatan. Jakarta: Rineka Cipta.

Noya, Allert Benedicto Ieuan. (2017). Ulkus Diabetikum, luka Pada Kaki Yang Perlu Segera Diobati. Alodokter. Diunduh dari:

http://www.alodokter.com/Ulkus_Diabetikum_Luka_Pada_ Kaki_Yang_Perlu_Segera_Diobati.

Nur, M., \& Mukhlis, H. (2020). Kualitas hidup ditinjau dari pengetahuan keluarga tentang perawatan lansia. Indonesia Berdaya, 1(1), 15-22.

Nursalam. (2013). Metodologi Penelitian Ilmu Keperawatan: Pendekatan Praktis Edisi 3. Jakarta: Rineka Cipta.

Nursalam. (2016). Metodologi Penelitian Ilmu Keperawatan: Pendekatan Praktis edisi 4. Jakarta: Rineka Cipta.

Oktaviyanti, Raini. (2013). Kualitas Hidup (Quality of Life) Seorang Penderita Tuberkulosis (TB). (Skripsi publikasi). Program Studi Psikologi Fakultas Dakwah dan Ilmu Komunikasi IAIN Sunan Ampel, Surabaya.

Pengertian, Karakteristik, dan Aspek-Aspek Kecemasan Menurut Para Ahli. Diunduh dari: http://www.universitas psikologi.com/2018/07/Pengertian_Karakteristik_dan_Aspe $\mathrm{k} \_$Kecemasan.html?m=1.

Rahmat, Wahyu Purwadi. (2010). Pengaruh Konseling Terhadap Kecemasan dan Kualitas Hidup Pasien Diabetes Melitus di Kecanmatan Kebakkramat. (Tesis publikasi). Program Pascasarjana Universitas Sebelas Maret, Surakarta.

Rapley, Mark. (2003). Quality of Life Research A Critical Introduction. London: SAGE Publications, Inc.

Rubbyana, Urifah. (2012). Hubungan Antara Stratregi Koping Dengan Kualitas Hidup Pada Penderita Skizofrenia Remisi Simptom. Fakultas Psikologi, Universitas Airlangga, Surabaya.

Salome, GM. et, al. (2011). Assesment of depressive symptoms in people with diabetes mellitus and foot ulcer. Rev Col Bras Cir. 2011;38(5):327-33.

Situmorang, L. L. (2009). Efektifitas Madu terhadap Penyembuhan Luka Ganggren Diabetes Melitus di RSUP H. Adam Malik Medan. Diakses tanggal 6 Januari 2020.

dari http://repository.usu.ac.id/handle/123456789/25284.

Soelistijo, Soebagijo Adi, dkk. (2015). Konsensus Pengelolaan dan Pencegahan Diabetes Melitus Tipe 2 di Indonesia 2015. Jakarta: PB PERKENI.

Suciati, Dewi. (2014). Gambaran Tingkat Kecemasan Pada Pasien Diabetes Melitus Dengan Luka Gangren Di Ruang Azzahra 2 RSI Jemursari Surabaya. dari: http://repository.nusa.ac.id/id/eprint/786.

Sugiyono. (2014). Cara Mudah Menyusun Skripsi, Tesis dan Disertasi. Bandung: Alfabeta.
Suryani, Ayu. (2016). Hubungan Antara Tingkat Kecemasan Dengan Kualitas Hidup Lanjut Usia di Panti Wredha Bhakti Panjang Surakarta. (Skipsi publikasi). Program Studi S1 Keperawatan Fakultas Ilmu Kesehatan Universitas Muhammadiyah Surakarta, Surakarta.

Syarif, Hilman. (2012). Kualitas Hidup Pasien Ulkus Diabetik di Poliklinik Endokrin RSUDZA Banda Aceh. (Skripsi dipublikasikan). Bagian Keilmuan Keperawatan Medikal Bedah PSIK-FK Universitas Syiah Kuala, Banda Aceh.

Townsend, Marry C. \& Morgan, Karyn I. (2018). Psychiatric Mental Health Nursing: Concept of Care In Evidence-Based Practice. Philadelphia: F. A. Davis Company.

Utami, Desni tri, dkk. (2014). Faktor-Faktor Yang Mempengaruhi Kualitas Hidup Pasien Diabetes Mellitus Dengan Ulkus Diabetikum. JOM PSIK, 1(2), 1.

WHO. Int. (2018). Diabetes Keyfacts. 